\title{
Effect of Parameter Variation of Viscoplastic Sea Ice Material Model on Ship Ice Collision
}

\author{
Lin Wang, Xiaogang Qian, Shuaishuai Zhu
}

\begin{abstract}
In this paper, the nonlinear finite element method is used to select the viscoplastic ice material model to simulate the ship ice collision. The dynamic structural response characteristics of sea ice collisions under different parameters such as different density and elastic modulus are studied respectively. The collision energy absorption law and collision force under different working conditions are revealed. The ice constitutive model under different parameters is obtained. The mechanism of the impact on ship ice collision is to provide reference for improving the ship's anti-ice load design.
\end{abstract}

Index Terms - viscoplastic ice material; density; modulus of elasticity; ship ice collision

\section{INTRODUCTION}

In recent years, many scientists have predicted that ice floes in the Arctic waters will disappear in 2050 due to global warming. But now the ice floes in the Arctic waters have begun to change from years of ice to ice of the year. The proportion of ice for many years has dropped from around $80 \%$ in the 1970 s to less than $45 \%$ today. In the past few years, there was a huge area of ice floes in the Arctic Ocean when it was summer. Compared with ice floes elsewhere, the Arctic waters have larger ice floes and thicker thicknesses, and they pose a greater threat to ships during collisions, thus having a significant impact on the environment and the safety of life and property. In order to overcome the problem of sea ice, we need to do a lot of research. The formation of sea ice is greatly affected by factors such as temperature and salinity of seawater. Therefore, the physical properties and mechanical properties of sea ice in different regions are also different; and the hardness of sea ice in different seasons is also very different. In the summer, part of the sea ice in the polar regions begins to melt, and the hardness is reduced. When entering the winter, the sea water will freeze rapidly, causing the new ice to combine with one year of ice and even years of ice. Increase.

Nowadays, many countries have been devoting themselves to the study of ice. The empirical formula method was used in the early study of ice breaking resistance. LINDQVIST [1] summarizes the results of real ship measurement and model test, and summarizes the empirical formula for calculating ship resistance in ice zone directly. In recent years, many

Lin Wang Doctor of Engineering, Professor, Postgraduate Tutor, Executive director of China Offshore Engineering Society of steel structures, Member of the Seventh Council of structural stability and fatigue branch of China Steel Structure Association. Member of the Structural Strength Group of the Specialized Committee of Ship Mechanics. China.

Xiaogang Qian Postgraduate of Naval Architecture and Ocean Engineering department of Jiangsu University of Science and Technology, China.+8613912206522

Shuaishuai Zhu Postgraduate of Naval Architecture and Ocean Engineering department of Jiangsu University of Science and Technology, China.+8618896658870 scholars have used numerical methods to study ship ice interaction. SU et al. [2] on the basis of empirical data, established a numerical model to study the ship's ice loads on ice contact, and analyzed the global and local ice loads systematically; LIU et al. [3] used nonlinear finite element software LS-DYNA to analyze the internal mechanism of ship and iceberg collision, and simulated the crack growth by element erosion. ZHOU et al [4] established a numerical model to simulate the dynamic ice load in the process of ice breaking, and compared with the experimental results; KIM et al [5] carried out ice cone compression experiments, and used LS-DYNA for numerical simulation to verify a set of ice material models. TAN and other [6] use discrete element numerical method to simulate the continuous ice breaking process in the ice layer.

This paper mainly uses ANSYS-DYNA software to simulate ship ice collision by changing the density and elastic modulus of sea ice.

\section{SHIP ICE COLLISION SCHEME}

In this paper, the ship model is modeled by finite element method using plastic follower material. The steel is EH32 low-temperature marine steel. The relevant values are shown in Table 1.

The constitutive relation of ice material is very complicated because of the difference of geographical location and environment. In this paper, the viscoplastic ice material model is made up of LS-DYNA MAT-019 and failure criterion ADD-MAT-EROSION. The relevant parameter settings are shown in table 2 .

The schematic diagram of collision is shown in Figure 1 below:

Tab.1 Parameters of EH32 stell

\begin{tabular}{cccccc}
\hline Density & $\begin{array}{c}\text { elastic } \\
\text { modulus }\end{array}$ & $\begin{array}{c}\text { Poisson's } \\
\text { ratio }\end{array}$ & $\begin{array}{c}\text { failure } \\
\text { strain }\end{array}$ & $\begin{array}{c}\text { yield } \\
\text { strength }\end{array}$ & $\begin{array}{c}\text { tensile } \\
\text { strength }\end{array}$ \\
\hline $\begin{array}{c}7850 \\
\mathrm{~kg} / \mathrm{m}^{3}\end{array}$ & $2.1 \mathrm{GPa}$ & 0.3 & 0.35 & $315 \mathrm{MPa}$ & $440 \mathrm{MPa}$ \\
\hline \multicolumn{7}{c}{ Tab.2 Viscoplastic ice material parameters } \\
\hline Density & elastic & $\begin{array}{c}\text { Poisson's } \\
\text { modulus }\end{array}$ & $\begin{array}{c}\text { Plastic } \\
\text { failure } \\
\text { deformation }\end{array}$ & $\begin{array}{c}\text { Maximum } \\
\text { failure } \\
\text { stress }\end{array}$ & $\begin{array}{c}\text { bending } \\
\text { strength }\end{array}$ \\
\hline $890 \mathrm{~kg} / \mathrm{m} 3$ & $8.3 \mathrm{GPa}$ & 0.3 & 0.01 & $10 \mathrm{MPa}$ & $2.5 \mathrm{MPa}$ \\
\hline
\end{tabular}

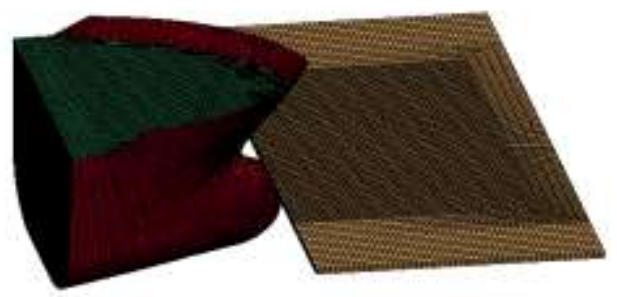

Fig.1 Schematic diagram of ship ice collision 


\section{INFLUENCE OF SINGLE PARAMETER IN SEA ICE CONSTITUTIVE MODEL}

\section{Influence of density variation in ice constitutive model}

In this study, the control variable method is used to control other parameters unchanged. The density of sea ice is 870 $\mathrm{kg} / \mathrm{m}^{3}, 890 \mathrm{~kg} / \mathrm{m}^{3}$ and $910 \mathrm{~kg} / \mathrm{m}^{3}$, and the simulation is carried out under the conditions $\mathrm{A}, \mathrm{B}$ and $\mathrm{C}$ respectively. By studying the different density of sea ice, this paper explores the change of stress and collision force and resistance of the ship's bow under different density, and then observes the damage and failure of ice.

The following figure 2 is the plastic strain diagram of the ship's bow under three working conditions. The figure shows that the plastic strain of bow is 0.13 in condition $\mathrm{A}, 0.18$ in condition $\mathrm{B}$ and 0.23 in condition $\mathrm{C}$. The plastic strain of bow increases in three working conditions, so the damage and deformation of bow is more and more serious.

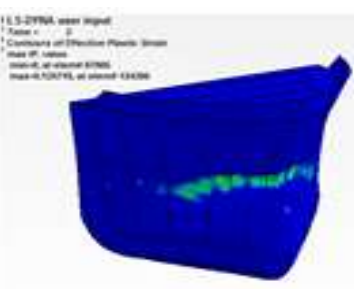

c.

A

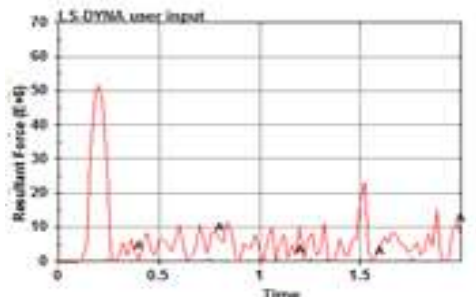

A

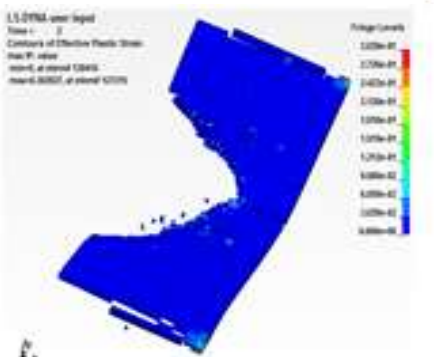

A

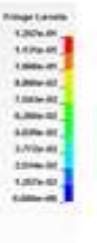

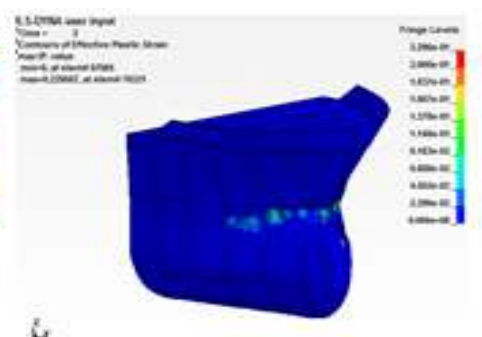

C

Fig.2 Plastic strain of bow at ending time

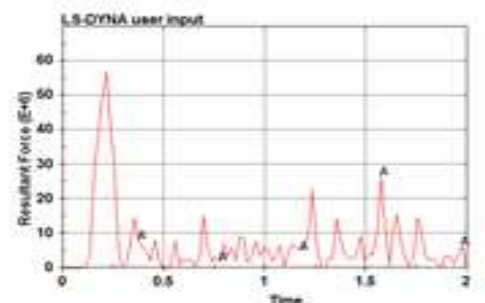

B

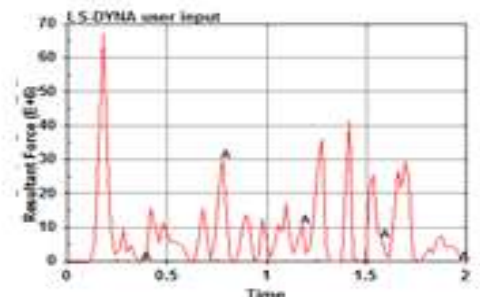

$\mathrm{C}$

Fig. 3 Curve of collision force-time under three conditions

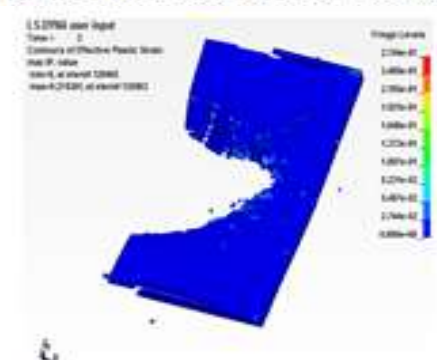

B

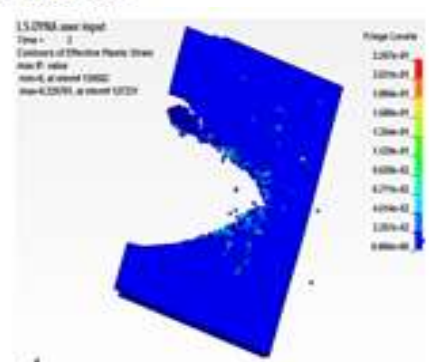

\&.

C

Fig.4 Plastic strain of ice at ending time

Figure. 3 above is the collision force-time curve of the first column under three conditions of ship ice collision. Through three working conditions, it can be seen that during the collision, the first column is subjected to a collision force of about $5.3 \times 10^{7} \mathrm{~N}$ for the first impact in the condition $\mathrm{A}$. Then, with the damage of the sea ice, the collision force of the first column is rapidly reduced. When it comes into contact with ice again, it increases again; in condition $\mathrm{B}$, the first column receives a collision force of about $5.8 \times 10^{7} \mathrm{~N}$ for the first time, and it also decreases rapidly, but the collision force is generally larger than $\mathrm{A}$. The force at the first collision of the first column in $\mathrm{C}$ is about $6.7 \times 10^{7} \mathrm{~N}$, and then the collision force is reciprocating throughout the collision, but in general, it is increased compared with the case B. The comparative analysis can be carried out through three kinds of working conditions. As the density of sea ice increases, the collision force of sea ice on the bow structure is increasing.

Fig. 4 is a plastic strain diagram of sea ice at the end of collision. It can be seen from the diagram that the plastic strain of $\mathrm{A}$ is 0.3 in the three working conditions, and 0.27 in $\mathrm{B}$ and 0.23 in $\mathrm{C}$. The plastic strain of sea ice is getting smaller and smaller in the three conditions, and the damage of sea ice is the most serious in condition $\mathrm{A}$, while the damage of $\mathrm{C}$ is slighter.

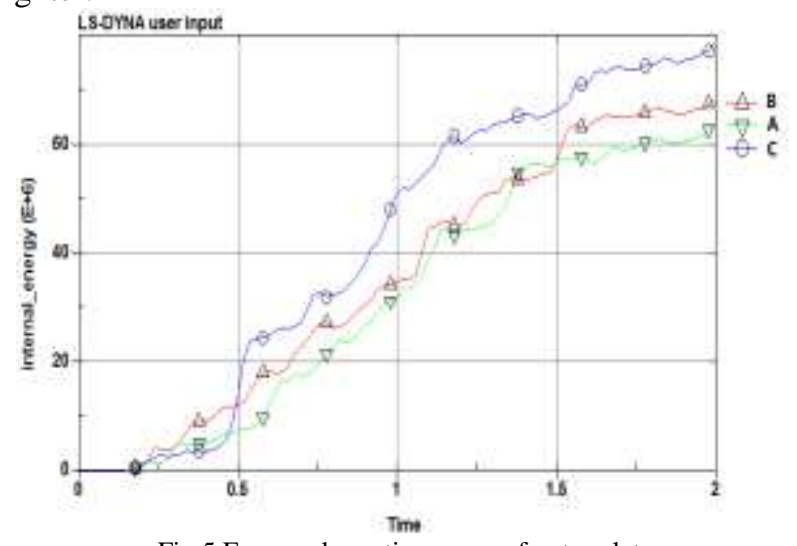

Fig.5 Energy absorption curve of outer plate 
Figure. 5 is the energy absorption curve of the bow plate during the collision process. The charts show that in the initial stage of collision, the energy absorption curves of the three conditions are similar, but there are also slight differences. Before $0.5 \mathrm{~s}$, the energy absorption of condition B is faster. At this stage, the damage of the outer and outer plates of condition $\mathrm{B}$ is more serious. After $0.5 \mathrm{~s}$, the energy absorption of condition $\mathrm{C}$ is obviously higher than that of the other two conditions. The energy is the least; at the end of the collision, the energy absorbed by condition $\mathrm{C}$ is the largest, the energy absorbed by condition $\mathrm{B}$ is smaller, and the energy absorbed by condition $\mathrm{A}$ is the least. According to the energy absorption, the damage and deformation of ship's bow to $\mathrm{C}$ is the most serious and the condition $\mathrm{A}$ is the lightest.

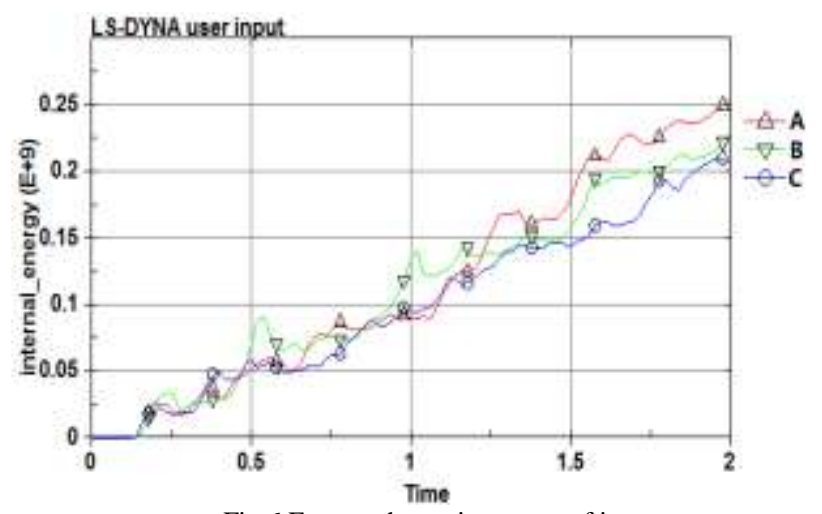

Fig.6 Energy absorption curve of ice

Fig. 6 is the energy absorption curve of sea ice in the course of collision. Because of the complex fragmentation characteristics of sea ice during the collision process, the energy absorption of sea ice under different conditions at the end of the collision is mainly compared in this diagram. At 2s, the sea ice in condition A absorbs the most energy, and the energy in condition $\mathrm{B}$ absorbs the second, and the energy in condition $\mathrm{C}$ absorbs the least. Therefore, it can be concluded that the damage and deformation of sea ice in condition $\mathrm{A}$ is the most serious, and the damage and deformation in condition $\mathrm{A}$ is the least.

Through the analysis of the damage and deformation of the bow, the collision force of the bow and the energy absorption of the outer plate, it is found that the damage and deformation of the bow is the most serious in condition $\mathrm{C}$, and the damage and deformation of working condition $\mathrm{A}$ is the least; and the damage and deformation of condition $\mathrm{A}$ is the most serious, while the damage and deformation of condition $\mathrm{C}$ is the least. From the analysis of bow and sea ice, it can be inferred that with the increase of sea ice density, sea ice hardens, its stiffness is strengthened, and the damage and deformation of ships are more serious during the collision process. Therefore, the choice of sea ice density should be carefully considered in the study of polar sea ice, after all, it affects the accuracy of the research results.

\section{Influence of elastic modulus in ice constitutive model}

The elastic modulus of sea ice is mainly affected by temperature. Relevant scholars have studied this. Listov [7] measured the elastic modulus of sea ice by using dynamic method, and found that the elastic modulus of the sea ice has a significant decrease when the temperature becomes higher. In this section, the $3.3 \mathrm{GPa}, 4.3 \mathrm{GPa}$ and $5.3 \mathrm{Gpa}$ modulus of elasticity of sea ice are set as working conditions A, B and C. The impact simulation is carried out by using finite element software ANSYS-DYNA through the change of the modulus of elasticity of sea ice.

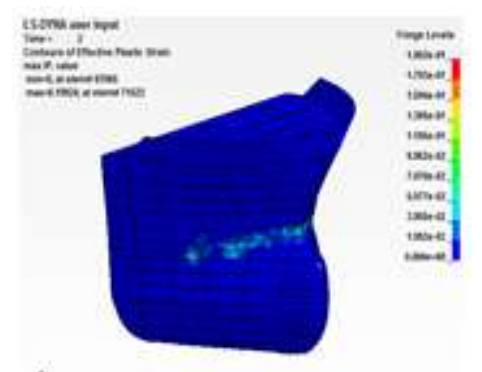

A

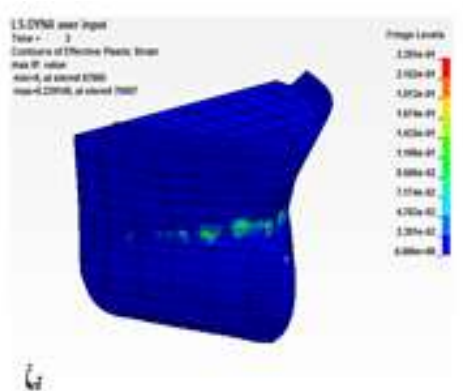

B

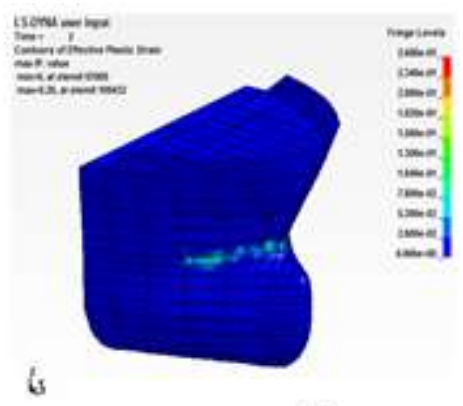

C

Fig.7 Plastic strain of bow at ending time

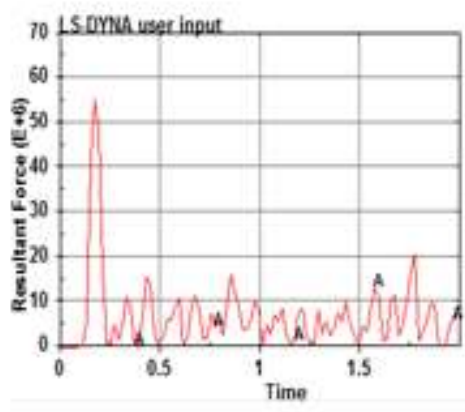

A

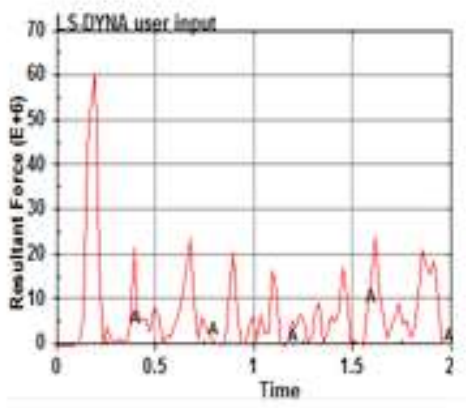

B

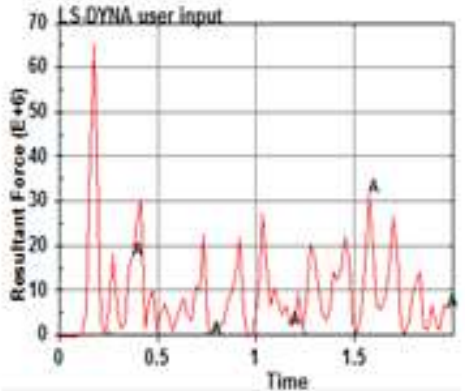

C 


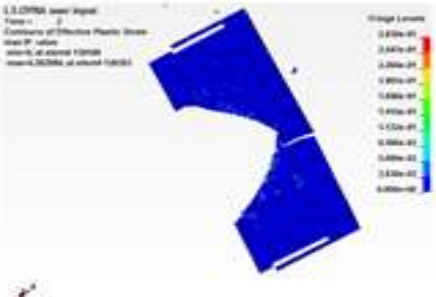

A

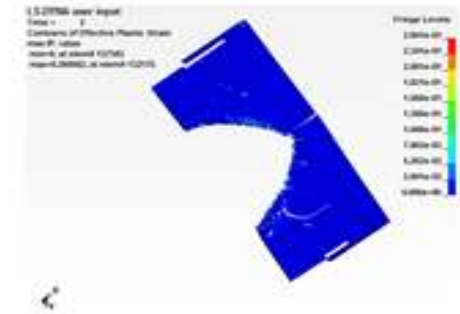

B

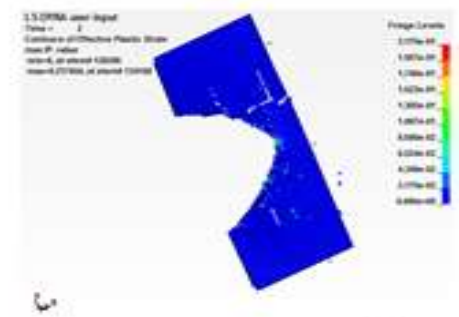

$\mathrm{C}$

Fig.9 Plastic strain of ice at ending time

Figure 7 above is the plastic strain diagram at the end of the bow. It can be seen from the diagram that the plastic strain in the three working conditions is in the collision contact area. The plastic strain in the bow of the ship is about 0.2 in condition A, about 0.24 in $\mathrm{B}$, and about 0.26 in $\mathrm{C}$. The plastic strain in the three conditions increases gradually. It shows that the damage and deformation of bow structure is the most serious in working condition $\mathrm{C}$, and the damage and deformation of $\mathrm{A}$ is the smallest.

Fig. 8 is the collision force time curve of three working conditions during ship ice collision. In condition A,the collision force on the head of the ship increases rapidly to about $5.4 \times 10^{7} \mathrm{~N}$ during the first collision, then decreases rapidly due to the breaking effect of sea ice, and then presents a reciprocating trend; in condition $B$, the collision force on the head of the ship increases to about $6 \times 10^{7} \mathrm{~N}$ during the first collision, and then decreases rapidly. However, compared with $\mathrm{B}$, the collision force is larger. While in condition $\mathrm{C}$, the bow collision force is about $6.5 \times 10^{7} \mathrm{~N}$, and then decreases rapidly and presents reciprocity, but the peak value increases compared with condition B. Therefore, with the increase of elastic modulus, the bow collision force of sea ice presents an increasing trend.

Fig. 9 is a plastic strain diagram of sea ice at the end of ship ice collision. In condition A, sea ice breaks. At this time, the plastic strain of sea ice is 0.28 . In condition $B$, sea ice has cracks from the middle and fractures from the outside to the inside. At this time, the plastic strain of sea ice is 0.26 . In condition $\mathrm{C}$, sea ice did not break from the middle, but cracks appeared in the periphery. At this time, the plastic deformation of sea ice was about 0.22 . It can be inferred from the three conditions that the breaking loss effect of sea ice decreases with the increase of elastic modulus.

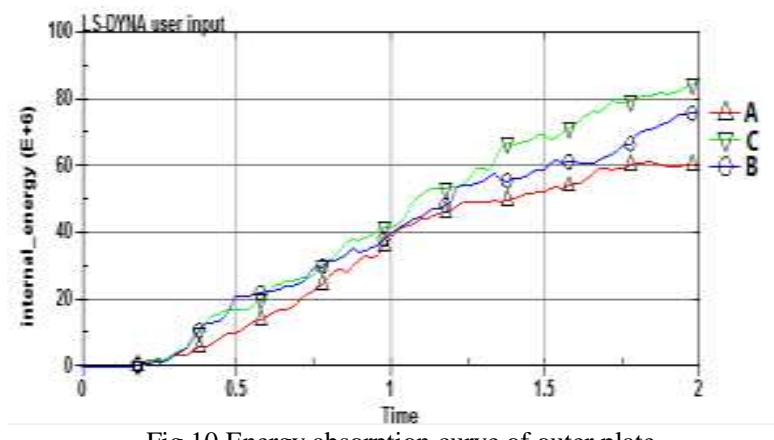

Fig.10 Energy absorption curve of outer plate

Fig. 10 is the energy absorption curve of the bow plate during ship ice collision. It can be seen from the diagram that the energy absorption rate of the outer plate in condition $\mathrm{A}$ is slower and the energy absorbed is the least in the whole process; the energy absorbed by the outer plate in condition $\mathrm{B}$ is between $\mathrm{A}$ and $\mathrm{C}$; and the energy absorbed by condition $\mathrm{C}$ is the fastest in the whole process, and the energy absorbed is the most in the end. From the energy absorption, it can be seen that the bow damage and deformation in condition $\mathrm{C}$ is more serious, followed by condition $\mathrm{B}$, and the damage in condition $\mathrm{A}$ is the least.

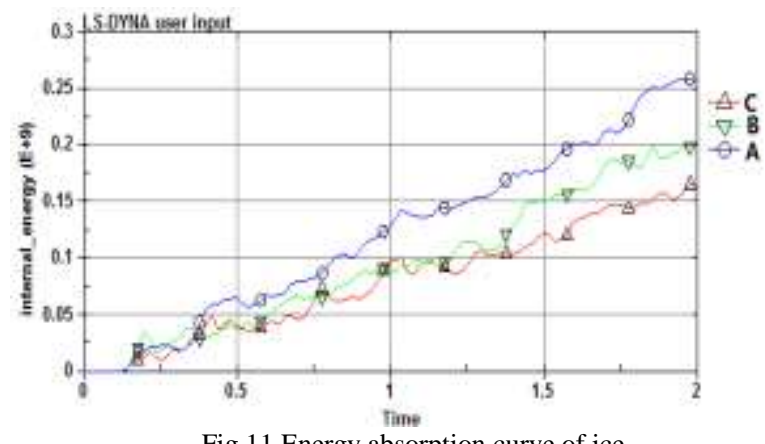

Fig.11 Energy absorption curve of ice

Fig. 11 is the energy absorption curve of sea ice in the course of collision. According to the diagram, the final energy absorption of condition $\mathrm{A}$ is the largest, followed by condition $\mathrm{B}$ and the least in condition $\mathrm{C}$. It can be concluded that the sea ice damage in condition $\mathrm{A}$ is the most serious, and the damage in condition $\mathrm{C}$ is the lightest compared with the first two working conditions.

Through the comparative analysis of the above three conditions, it is found that in the three conditions, the stress and strain, collision force and energy absorption of the bow are the largest in condition $\mathrm{C}$, the second in condition $\mathrm{B}$ and the smallest in condition $\mathrm{A}$. The failure of sea ice in condition $\mathrm{A}$ is the most serious, and the condition is B second, and the condition $\mathrm{C}$ is the smallest. Through the comprehensive analysis of the bow and sea ice, the hardening phenomenon of sea ice occurs in the process of increasing the elastic modulus, which leads to the strengthening of the stiffness of sea ice, and the damage and deformation of the bow is more serious.

\section{INFLUENCE OF MULTIPLE PARAMETERS IN THE CONSTITUTIVE MODEL OF SEA ICE}

Through the previous study of single parameters such as density and elastic modulus in the constitutive model of sea ice, it can be found that the change of single parameter has certain influence on ship ice collision. However, many parameters of sea ice encountered by ships in different ice areas and even in different seasons may vary, so in this section, we will study the effect of simultaneous changes of density and elastic modulus in the constitutive model of sea ice based on the previous results. In this section, $870 \mathrm{~kg} / \mathrm{m} 3$ and $3.3 \mathrm{GPa}$ constitutive models of sea ice are set as condition A, $910 \mathrm{~kg} / \mathrm{m} 3$ and $5.3 \mathrm{GPa}$ constitutive models as condition B, 
and the two working conditions are compared and analyzed by finite element method.

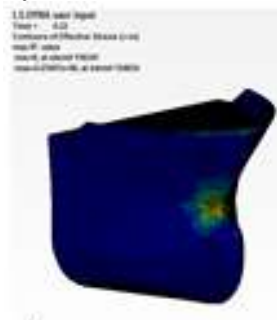

6

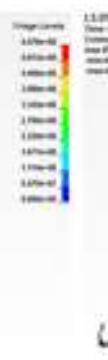

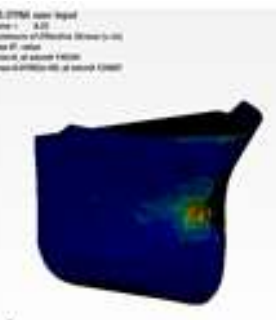

B
Fig.12 Stress nephogram of the bow when it first collides

Fig.12 is the stress cloud map of the bow in two working conditions when the ship is first collided. The stress in the condition $\mathrm{A}$ is about $5.6 \times 10^{8} \mathrm{~Pa}$ at this time. The stress in condition $\mathrm{B}$ is about $6 \times 10^{8} \mathrm{~Pa}$. Compared with the two, the stress on the bow of the ship in condition $\mathrm{B}$ is greater.

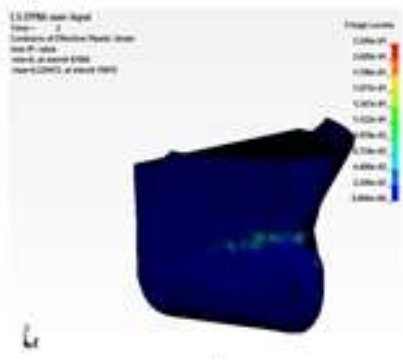

A

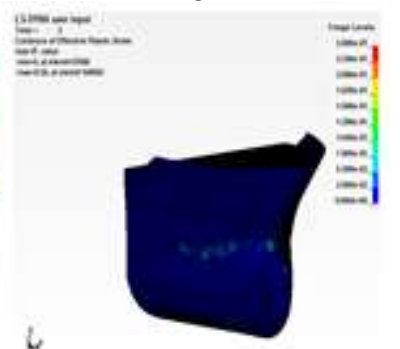

B
Fig.13 Plastic strain of the bow at the ending

In Figure 13, for the whole collision process, the plastic strain of bow is 0.22 in condition $\mathrm{A}$ and 0.26 in $\mathrm{B}$. By comparing the two cases, the plastic strain of bow is greater in B. Through the comparative analysis of stress and strain, it can be deduced that the damage and deformation of bow from sea ice is more serious in condition $\mathrm{B}$.

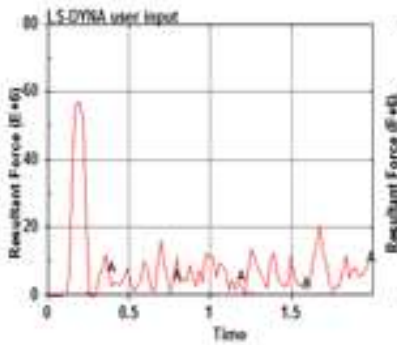

A

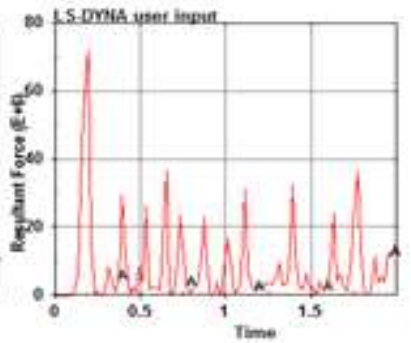

B
Fig.14 Collision force-time curve of the stem

According to the time curve of the collision force of the head column in Fig.14 above, it can be seen that in the first collision, the collision force of the head column in condition $A$ is about $5.5 \times 10^{7} \mathrm{~N}$, and the collision force of the head column in condition B is about $7.2 \times 10^{7} \mathrm{~N}$. There is a large difference in the collision force between the two conditions. In the later impact process, it can be seen that the impact force of the head column in mode B is higher than that of the condition A.

Fig.15 shows the stress distribution of sea ice during the first collision. It can be seen from the chart that the stress of sea ice in condition $\mathrm{A}$ is about $8.8 \times 10^{7} \mathrm{~Pa}$ at this moment, while that of sea ice in condition $\mathrm{B}$ is about $9.7 \times 10^{8} \mathrm{~Pa}$. In the plastic strain diagram of the last moment in figure.16, the plastic strain of sea ice in condition $\mathrm{A}$ is 0.26 . In condition $\mathrm{B}$, the plastic strain of sea ice is 0.22 . Through the analysis of stress and strain in two conditions, it can be seen that the sea ice can bear more force in condition $\mathrm{B}$ than in condition $\mathrm{A}$, that is, the sea ice in condition $\mathrm{B}$ is harder.

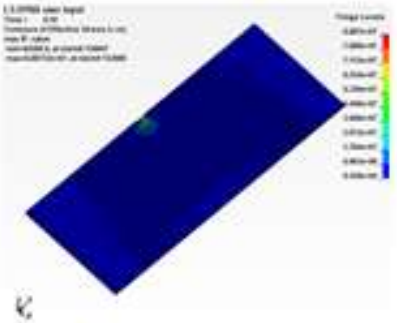

A

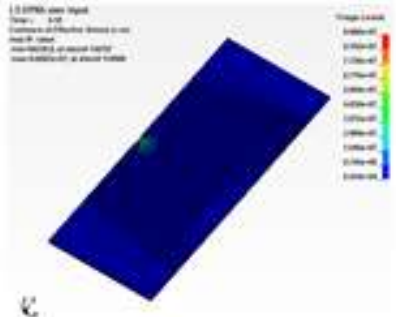

B
Fig 15 Stress nephogram of the ice when it first collides

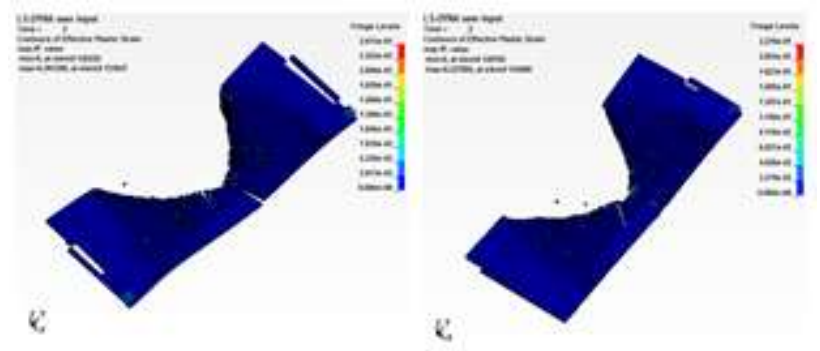

A

Fig 16 Plastic strain of the ice at the ending

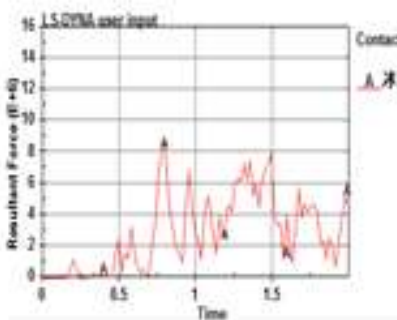

A

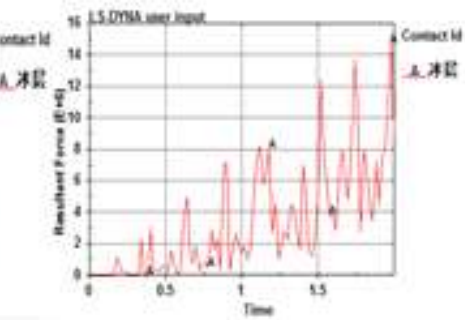

B

Fig. 17 Collision force-time curve of ice

Fig.17 is the collision force time curve of sea ice in the course of collision. When the impact force of sea ice in working condition A reaches its maximum value, the damage effect of sea ice will occur after the impact, and the plastic strain of sea ice will be large, so it will decrease rapidly. However, the impact force presents a nonlinear fluctuation trend due to the incomplete rupture of sea ice. In condition $\mathrm{B}$, the impact force of sea ice is the same as that in condition A, but it increases gradually in the later period. The comparison of the two working conditions shows that the impact force of sea ice in condition $\mathrm{B}$ is much greater than that in working condition A, that is, the sea ice in condition B is more difficult to break. Sea ice hardness is enhanced relative to A.

Fig. 18 is the energy absorption time curve of sea ice during the whole collision process. It can be seen from the diagram that at the beginning of the collision, there is a small peak in both cases, and the peak in case A is slightly higher than that in case $\mathrm{B}$, which indicates that the damage effect of sea ice in case A is more serious than that in case B at the beginning of the collision. From the overall energy absorption, the energy 
absorption of the condition A is basically higher than that of the condition $\mathrm{B}$ at any time. At the end of the collision, the energy absorption of condition $\mathrm{A}$ is $0.75 \times 10^{8} \mathrm{~J}$ more than that of condition $\mathrm{B}$, which is about $38 \%$ higher than that of $\mathrm{B}$. The energy absorption reaction is the damage and deformation of the structure. It is inferred that the damage and deformation of condition $\mathrm{A}$ is more serious than that of condition $\mathrm{B}$, and the damage and deformation of condition B is less.

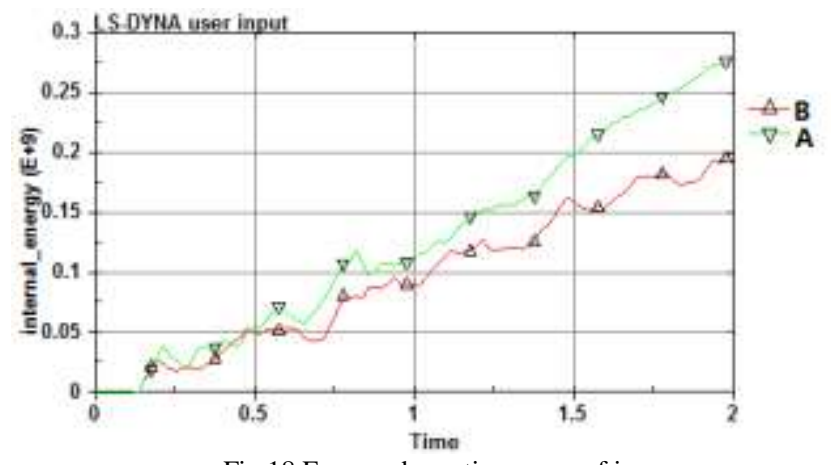

Fig.18 Energy absorption curve of ice

Through the above analysis, it can be seen that the plastic failure deformation of working condition B is lighter than that of working condition $\mathrm{A}$ in the whole collision process, and the sea ice in working condition B can withstand greater force, and the breaking loss effect of working condition B is lighter than that of working condition A. It can be determined that ice hardening is more serious in working condition $\mathrm{B}$, and Hai Bing stiffness increases even more.

By comparing the two conditions, it is found that when the two parameters of the constitutive model of sea ice change, the maximum values of stress, strain and collision force on the bow of the ship in the process of collision are larger than those of the single parameter. And through the analysis of the damage, collision force and energy of the sea ice, the hardening phenomenon is more serious, the stiffness is also greater, the sea ice is more difficult to break, so that the damage to the bow of the ship is more serious. It can be deduced that when the density and elastic modulus of sea ice increase, the damage and deformation of bow will be more serious. If the density and elastic modulus continue to increase, even the bow damage will occur. In the study of ship ice collision, the choice of density and elastic modulus in the constitutive model of sea ice should also be based on the situation studied.

\section{CONCLUSION}

In this paper, by using ANSYS-DYNA software to simulate the collision between the bow and sea ice, the variation of sea ice density, elastic modulus and other parameters in the same constitutive model of sea ice are analyzed. The main conclusions are as follows:

1) According to the stress-strain, collision force, energy and stress-strain of the ship under different sea ice densities, it is known that the stress-strain and collision force on the bow of the ship increase with the increase of sea ice density, and the stress of sea ice increases with the increase of sea ice density in this process. That is, sea ice increases slightly with the increase of density.

2) According to the stress-strain, collision force, energy and stress-strain of ship hull under different modulus of elasticity of sea ice, we know that the stress-strain and collision force of ship bow increase with the increase of modulus of elasticity, and the stress of sea ice increases with the increase of density. That is, when the elastic modulus of sea ice becomes greater, the hardness will increase to a certain extent, and the damage to the hull will also increase.

3) By comparing and analyzing the changes of ice density and elastic modulus in the same ice constitutive model, the collision force of bow column is $7.2 \times 10^{7} \mathrm{~N}$ with the increase of ice density and elastic modulus. The impact force is greater than that of a single parameter of density and modulus of elasticity. It can be seen that the hardness of sea ice is obviously greater than that of a single parameter change, and the damage and deformation of the bow is more serious, so ships navigating in the ice zone should consider whether to strengthen the hull design according to the situation of the ice zone.

\section{REFERENCES}

[1]LINDQVIST G. A straightforward method for calculation of ice resistance of ships[C]//The $10^{\text {th }}$ International Conference on port and Ocean Engineering under Arctic Conditions. Lulea,Sweden, 1989,2:722-735.

[2]SU B,RISKA K,MOAN T. A numerical method for the prediction of ship performance in level ice [J].Cold Regions Science and Technology, 2010,60(3): 177 - 188.

[3]LIU Z,AMDAHL J, LOSET S. Integrated numerical analysis of an iceberg collision with a foreship structure[J].Marine Structures, 2011,24(4):377 - 395.

[4]ZHOU L,RISKA K, MOAN T, et al. Numerical modeling of ice loads on an icebreaking tanker:comparing simulations with model tests[J].Cold Regions Science and Technology,2013,87:33 - 46.

[5]KIM H. Simulation of compressive'crone-shaped'ice specimen experiments using LS-DYNA [C]//13 ${ }^{\text {th }}$ International LS-DYNA Users Conference. Detroit,MI, 2014.

[6]TAN X,RISKA K,MOAN T.Performance simulation of a dual-direction ship in level ice [J].Journal of Ship Research,2014,58(3):168-181.

[7]E.M. Listov. Study of Elastic properties of an ice Cover on Arctic.Proc.Int.Conf.POAC,Vol 1.,Fairbanks,pp.349-359.

Lin Wang Doctor of Engineering, Professor, Postgraduate Tutor, Executive director of China Offshore Engineering Society of steel structures, Member of the Seventh Council of structural stability and fatigue branch of China Steel Structure Association. Member of the Structural Strength Group of the Specialized Committee of Ship Mechanics. China

Xiaogang Qian Postgraduate of Naval Architecture and Ocean Engineering department of Jiangsu University of Science and Technology, China.+8613912206522

Shuaishuai Zhu Postgraduate of Naval Architecture and Ocean Engineering department of Jiangsu University of Science and Technology, China.+8618896658870 